\title{
PROCORAD's international proficiency testing for radio-bioassays
}

\author{
R. Fottorino ${ }^{1}$, M. Ruffin ${ }^{1}$, and Ph. Bérard ${ }^{2}$ \\ 1 CEA Cadarache, LABM, Bâtiment 102, 13108 Saint-Paul-Lez-Durance, France \\ 2 PROCORAD Scientific Council, CEA DSV, BP 6, 92265 Fontenay-aux-Roses Cedex, France
}

Received: 3 August 2010 / Accepted: 19 August 2010

\begin{abstract}
In France, the Clinical Biochemistry Laboratories (CBL) are in charge of the monitoring of nuclear workers. These laboratories must be accredited and have ministerial certification. The accreditation of radiobioassay analyses requires notably Proficiency Testing (PT) between laboratories. One of the most important PT providers, in this field, is the PROCORAD association. The specifics are to provide real biological samples spiked with various radionuclides and to send them around international CBL. The results obtained by the all laboratories are both statistically and anonymously exploited, thanks to homemade software entitled Procostat. PROCORAD PT's program answers to a definite demand from laboratories in charge of monitoring workers, for some years more than 70 participants from all over the world have signed up to participate in these comparison exercises. Apart from an assessment of the different laboratories performance, the comparison exercises organized by the PROCORAD's association enable the Clinical Biochemistry Laboratories to evaluate the techniques implemented in terms of accuracy, reproducibility and specificity.
\end{abstract}

Keywords: PROCORAD; proficiency testing; comparison exercises; techniques; performance

\section{Introduction}

In France, the on site CBL (Clinical Biochemistry Laboratories) at nuclear facilities are involved in monitoring of workers exposed to a risk of contamination. Each CBL has to be accredited according to the ISO/IEC 17025 standard [1], and authorized by the Nuclear Safety Authority $(\mathrm{ASN})$. One of the accreditation key points is to participate in external quality controls which are the proficiency testing between laboratories that allow an objective appreciation of analytical performance of the laboratory.

One of the most important PT's providers, in this area, is that organized by the PROCORAD association.

\section{PROCORAD association}

Created in 1995 by the biologists of AREVA and Atomic Energy Commission (CEA), PROCORAD is the "Association for the Promotion of Quality Controls in Radiotoxicological Bioassays" [2]. Its purpose is to organize, according to ISO/IEC 17043 standard [3], an annual proficiency testing between laboratories throughout the world in different analytical fields and under the technical responsibility of the organizer laboratories from CEA and AREVA sites.

The participant laboratories may be environmental or biological laboratories.
Nine comparison exercises are organized:

- Tritium in urine.

- Actinides in urine (except Uranium) [4].

- Uranium in urine [5].

- Actinides in fecal ashes.

- Carbone 14 in urine.

- Strontium 90 in urine.

- Gamma-X emitters in urine.

- Surprise urine.

- Polonium in urine.

The annual schedule of this preparation is very strict:

- From October to February: preparation of the biological samples overloaded by certified radioactive (CRM) standard solutions.

- In December: registration of the different laboratories via Procorad website and communication of a specific anonymous number.

- End of February: sending of samples to participant laboratories.

- End of April: sending of results and answers to technical questionnaire by participant laboratories.

- From May to mid June: statistical treatment of results via a specially designed software entitled "Procostat" and preparation of the presentation by the organizer laboratories. 


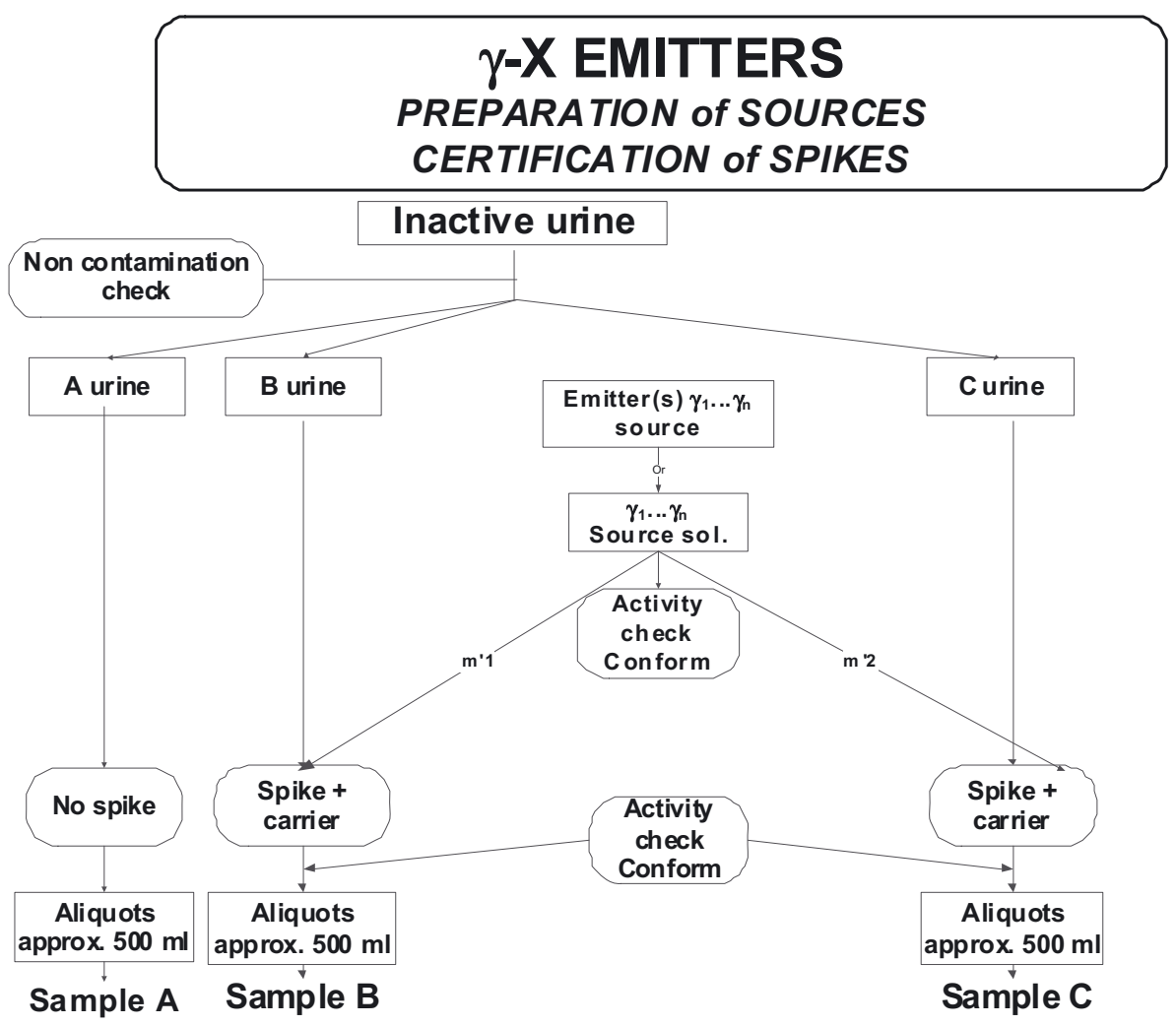

Fig. 1. Preparation of the gamma-X comparison exercise.

- Mid June: annual meeting with presentation of results by number of anonymity and technical communications and workshops.

- End of October: sending of a CD Rom with presentations, minutes of each exercise and positioning of each laboratory (own result versus target value). The best methods, those whose bias in regard with the target value is minimal, are also published in a "collection of techniques", always keeping anonymity.

PROCORAD is certified ISO 9001 since 2008.

\section{Organization of comparison exercises}

For example, the preparation of the emitter gamma-X comparison exercise performed by the CBL of Cadarache, a CEA site in the south of France, is developed in this article.

The first step is the collection of urine from non exposed persons, e.g., Figure 1.

- Approximately 100 liters of urine are collected on sulfamic acid and chlorhydric acid, filtered and shared in 3 parts, equivalent in volume; a non radioactive sample, corresponds to sample A, parts B and C are overloaded by a determined mass or activity of certified $\mathrm{X}$ and gamma emitter solutions and are nominated sample B and $\mathrm{C}$.

Secondly, many checks are made by the organizer laboratory:

- Check the activities of the certified standard solution (CRM) used for overloading and of series of samples af- ter overloading. After conformity of these checks, the organizer laboratory sends the samples to the participant laboratories.

Every laboratory receives approximately $500 \mathrm{ml}$ of each sample whose activity is less than 10 Bq. ${ }^{-1}$.

Each laboratory has to analyze the samples with its own technique and to express their results in terms of measured activities associated with the global uncertainties via the web site of the association.

After reception of each result, the statistical treatment [6-8] with "Procostat" software is performed by using statistical tests depending on the number of results to determine which result will be kept or excluded:

- Grubbs, student, Z Score and Zeta score tests if the number of laboratories is greater than 30 .

- Dixon test in addition for lower than 30 laboratories.

Arithmetical and geometrical mean values are calculated according to the retained results and a first diagram of repartition by anonymous number is made, e.g., Figure 2.

Then, two other diagrams are made, e.g., Figure 3.

One corresponds to the result and uncertainty of each laboratory according to the target value and its uncertainty. The second one presents the bias in percentage in relation with the target value.

In June, the annual meeting allows the participant laboratory to assess his accuracy according to the results sent. Moreover, the organizer presents the comparisons of performance between different chemical methods and counting equipment. 


\begin{tabular}{|c|c|c|c|c|c|c|c|c|c|}
\hline & & & & 66 & \multirow[b]{4}{*}{60} & & \multirow[b]{4}{*}{51} & & \\
\hline & & & & 53 & & & & & \\
\hline & & & & 52 & & & & & \\
\hline & & & & 25 & & & & & \\
\hline & & & & 23 & 46 & & 28 & & \\
\hline & & & 49 & 12 & 45 & 43 & 27 & & \\
\hline 68 & & & 48 & 5 & 36 & 37 & 8 & & \\
\hline 57 & 6 & 39 & 31 & 3 & 19 & 17 & 1 & 69 & 13 \\
\hline $\begin{array}{c}3,90 \mathrm{E}+00 \\
<=4,20 \mathrm{E}+00\end{array}$ & $\begin{array}{l}>4,20 \mathrm{E}+00 \\
<=4,50 \mathrm{E}+00\end{array}$ & $\begin{array}{l}>4,50 \mathrm{E}+00 \\
<=4,80 \mathrm{E}+00\end{array}$ & $\begin{array}{l}>4,80 \mathrm{E}+00 \\
<=5,10 \mathrm{E}+00\end{array}$ & $\begin{array}{l}>5,10 \mathrm{E}+00 \\
<=5,40 \mathrm{E}+00\end{array}$ & $\begin{array}{l}>5,40 \mathrm{E}+00 \\
<=5,69 \mathrm{E}+00\end{array}$ & $\begin{array}{l}>5,69 \mathrm{E}+00 \\
<=5,99 \mathrm{E}+00\end{array}$ & $\begin{array}{l}>5,99 \mathrm{E}+00 \\
<=6,29 \mathrm{E}+00\end{array}$ & $\begin{array}{l}>6,29 \mathrm{E}+00 \\
<=6,59 \mathrm{E}+00\end{array}$ & $\begin{array}{c}>6,59 \mathrm{E}+00 \\
6,89 \mathrm{E}+00\end{array}$ \\
\hline
\end{tabular}

\section{Column with target value}

Fig. 2. Diagram of repartition of results for one $\mathrm{X}$ or gamma emitter.
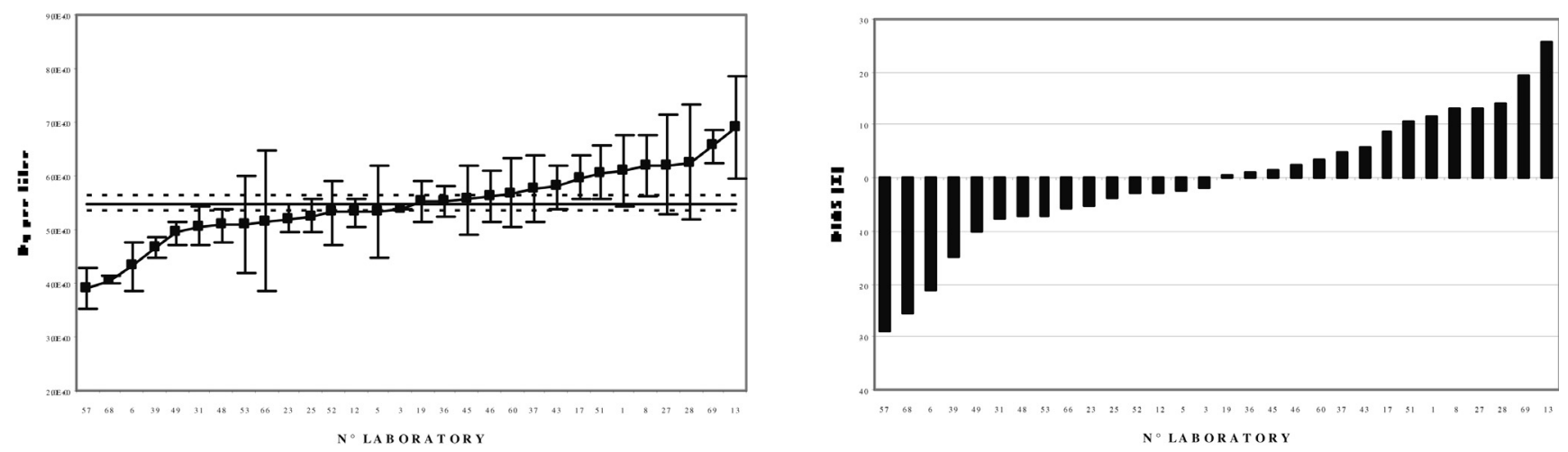

Fig. 3. Diagrams of results with uncertainties and bias (\%) regarding to the target value.

For instance, for the 2010 gamma-X comparison exercise, the conclusion deals with 3 themes:

- the performance of the detectors for radioactive iodine (Fig. 4),

- the evolution of the performance between 2003 and 2010 (Fig. 6),

- the global 2010 performance (Fig. 7).

The $\mathrm{X}$ and gamma measurements can be made with different types of hyperpure Germanium detectors (type N, type P, XTra or BeGe detectors) or with an association of these detectors. It is important to analyze the performance of each system.

The best performance is obtained by XTra detectors because of their wide field of measurement (from low level to high level energies). The mean bias is $6 \%$ with a low dispersion $(\sigma)$. The $\mathrm{N}$ detectors give also good results. This is in correlation with Figure 5 above, which represents the efficiency of the different kind of detectors. BeGe and $\mathrm{P}$ detectors do not appear so efficient for iodine detection, as the mix of 2 detectors.

Figure 6 represents the evolution of biases over years for each radionuclide and shows:

- the very good global performance of detection and quantification for the very low levels of gamma-X emitters used in the samples $\left(<10\right.$ Bq. $\mathrm{l}^{-1}$ for each radionuclide),
- the significant improvement in the detection of ${ }^{129} \mathrm{I}$,

- the constant relative difficulty of quantification of some radionuclides due to their high energy $\left({ }^{22} \mathrm{Na}\right)$ or to their many rays of emission $\left({ }^{152} \mathrm{Eu}\right)$.

Figure 7 makes the synthesis for each radionuclide:

- the number of laboratories which have given an answer,

- the target value,

- the number of outliers after statistical treatment,

- the results given by the outliers and their bias in relation to the target value,

- the bias field of the selected laboratories, and

- the performance between $-25 \%$ and $+50 \%$ which is the field of accuracy recommended by ANSI (American National Standards Institute) [9], on the one hand for the selected laboratories, and on the other hand for all the laboratories - some outliers being located in the ANSI field of performance.

This figure shows the performance of the group in comparison with the criteria of acceptance for a large number of radionuclides. This number covers a large range of $\mathrm{X}$ and Gamma energies. Technical discussions are also fruitful to compare equipment, counting geometries, counting time and procedures of each CBL. 


\section{$129|-125|$}

\begin{tabular}{|c|c|c|c|c|c|c|c|}
\hline & \multirow[t]{2}{*}{ Nb } & \multicolumn{2}{|c|}{$\begin{array}{c}125 \mathrm{I}-\mathrm{B}+\mathrm{C} \\
\text { Bias (\%) }\end{array}$} & \multicolumn{2}{|c|}{$\begin{array}{c}{ }^{129} \mathrm{I}-\mathrm{B} \\
\text { Bias (\%) }\end{array}$} & \multicolumn{2}{|c|}{$\begin{array}{l}{ }^{125}\left|+{ }^{129}\right| \\
\text { Bias (\%) }\end{array}$} \\
\hline & & Mean & $\mathbf{s}$ & Me & $n s$ & & 5 \\
\hline $\mathbf{N}$ & 6 & 10.5 & 8.9 & 8.2 & 7.2 & 9.7 & 8.2 \\
\hline $\mathrm{BeGe}$ & 4 & 21.6 & 13.4 & 9 & 6.8 & 17.4 & 12.8 \\
\hline XTra & 2 & 7.25 & 5.7 & 3.5 & 2.1 & 6 & 4.9 \\
\hline $\begin{array}{l}\mathrm{P} / \mathrm{N} \\
(+2 \text { excluded })\end{array}$ & 2 & $\begin{array}{l}25.2 \\
(+158 \%-\end{array}$ & $\begin{array}{c}9 \\
-225 \%) \\
\end{array}$ & $\begin{array}{l}26 \\
(+152 \%\end{array}$ & $\begin{array}{c}- \\
+500 \%) \\
\end{array}$ & 25.4 & 7.8 \\
\hline $\mathbf{P}$ & 1 & 21 & 1.4 & 21 & - & 21 & \\
\hline $\mathrm{P} / \mathrm{BeGe}$ & 1 & 38.5 & 3.5 & 38.5 & - & 38.5 & \\
\hline
\end{tabular}

Fig. 4. Performance of the detectors for the ${ }^{129} \mathrm{I}$ and ${ }^{125} \mathrm{I}$ detection.

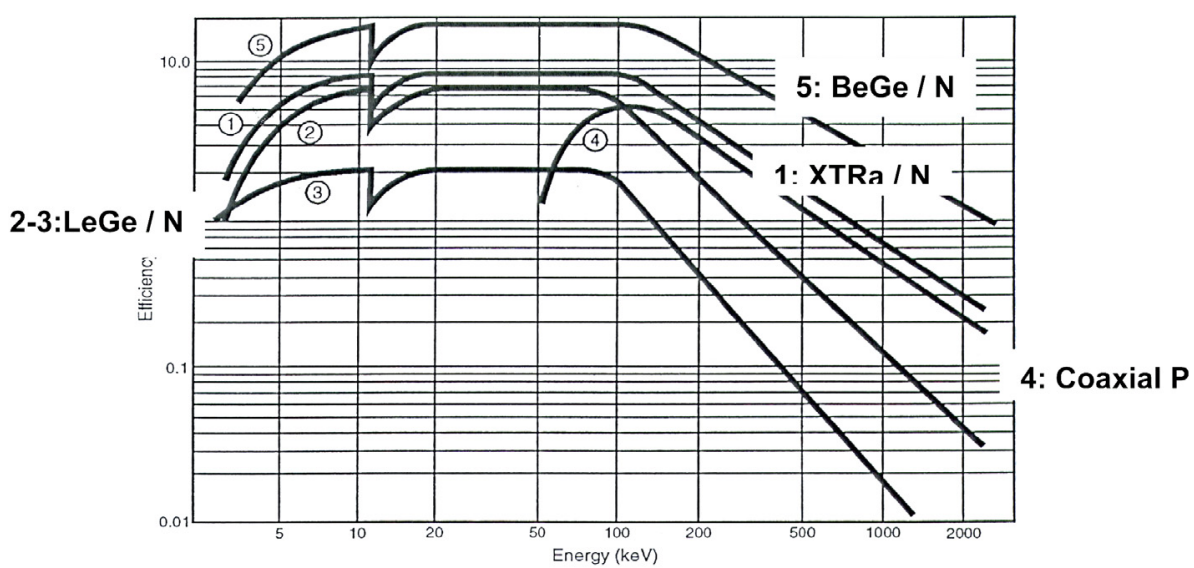

Fig. 5. Efficiency of the different kinds of gamma-X detectors.

\section{$\gamma$-X EMITTERS INTERCOMPARISON performances $2003-2010$}

\begin{tabular}{|c|c|c|c|c|c|c|c|}
\hline 1291 & $\begin{array}{l}2010 \\
+\mathbf{3} \% \\
\end{array}$ & $\begin{array}{r}2009 \\
+3.2 \% \\
\end{array}$ & $\begin{array}{l}2007 \\
+6 \%\end{array}$ & $\begin{array}{r}2006 \\
+23 \% \\
\end{array}$ & $\begin{array}{c}2005 \\
+13.4 /-0.3 \%\end{array}$ & $\begin{array}{r}2003 \\
+41 \% \\
\end{array}$ & $\begin{array}{c}\text { mean } \\
+14.9 \%\end{array}$ \\
\hline 125 & \multicolumn{2}{|c|}{$\begin{array}{c}2010 \\
+\mathbf{8 . 3} / \mathbf{+ 8 . 6} \%\end{array}$} & \multicolumn{2}{|c|}{$\begin{array}{l}2006 \\
-1.8 \%\end{array}$} & & & -- \\
\hline${ }^{57} \mathrm{Co}$ & $\begin{array}{l}2010 \\
-4.1 \%\end{array}$ & \multicolumn{2}{|c|}{$\begin{array}{r}20108 \\
-0.7 / 0 \% \\
\end{array}$} & $\begin{array}{l}2005 \\
1 / 1.2 \%\end{array}$ & $\begin{array}{c}2001 \\
+0.9 i-0.4 \%\end{array}$ & & $-1 \%$ \\
\hline${ }^{22} \mathrm{Na}$ & $\begin{array}{l}2010 \\
-9.3 \% \\
\end{array}$ & \multicolumn{2}{|c|}{2006} & 2003 & & & $-9.6 \%$ \\
\hline${ }^{137} \mathrm{Cs}$ & \multicolumn{2}{|c|}{$\begin{array}{c}2010 \\
(+\mathbf{1 0 . 5} /+\mathbf{1 1 . 8} \%)\end{array}$} & $\begin{array}{r}2009 \\
+5.4 \% \\
\end{array}$ & $\begin{array}{c}2007 \\
+6.9\end{array}$ & $\begin{array}{r}2006 \\
+0.5 \% \\
\end{array}$ & $\begin{array}{r}2005 \\
+2.3 \% \\
\end{array}$ & $+3.8 \%$ \\
\hline${ }^{152} \mathrm{Eu}$ & $\begin{array}{l}2010 \\
-6 \%\end{array}$ & $\begin{array}{r}2008 \\
+1.2 \%\end{array}$ & $\begin{array}{l}2007 \\
-6.2 \%\end{array}$ & $\begin{array}{l}2004 \\
-8.2 \%\end{array}$ & $\begin{array}{r}20000 \\
-5.3 / 3\end{array}$ & & $-4.64 \%$ \\
\hline
\end{tabular}

Fig. 6. Evolution of the performance between 2000 and 2010

\section{Conclusion}

PROCORAD, a French certified ISO 9001 association, provides a large range of annual radiotoxicological comparison exercises, at low levels of activity. PROCORAD's organization applies ISO 17043 requirements for proficiency testing. These exercises correspond to a strong demand of laboratories working in the human and environmental radiotoxicological fields, in order to objectively evaluate their analytical performance. In addition, these comparison exercises enter the field of external quality evaluations which are more and more an obligation for accreditation and ministerial certification which are now the general rule for allowing the laboratories to exercise.

In medical laboratories, international proficiency tests are widely used for the evaluation of their performance in terms of accuracy and reproducibility [10], the validation of methods used, the assessment of effectiveness, the 


\section{Y-X EMITTERS INTERCOMPARISON performances 2010}

\begin{tabular}{|c|c|c|c|c|c|c|c|c|c|}
\hline RN & $\frac{\ddot{z}}{\bar{m}}$ & $\begin{array}{l}\text { Nb labs } \\
\text { / results }\end{array}$ & target & \multicolumn{3}{|c|}{ Outliers } & $\begin{array}{l}\text { Bias field 吹 } \\
\text { Select.labs }\end{array}$ & \multicolumn{2}{|c|}{$\begin{aligned} & \text { Selected labs total } \\
& 25 x+50 x-25 x+50 x \\
&\end{aligned}$} \\
\hline 1251 & B & 17 & 8.68 & 1 & 22.4 & +158 & $-20 \quad+42$ & $16 / 16$ & $16: 17$ \\
\hline 1251 & $c$ & 17 & 6.69 & 1 & 21.8 & +226 & $-35 \quad+42$ & $15 / 16$ & $15 / 17$ \\
\hline 1291 & B & 17 & 7.13 & 2 & $\begin{array}{l}18 \\
42.5 \\
\end{array}$ & $\begin{array}{l}+152 \\
+496 \\
\end{array}$ & $\begin{array}{ll}-26 & +21\end{array}$ & $14 / 15$ & $14 / 17$ \\
\hline 152Eu & Bi & 39 & 5.40 & 1 & 7.96 & +47 & $-24+12$ & $38 / 36$ & $39 / 39$ \\
\hline 22Ha & $c$ & 38 & 5.14 & 1 & 3.47 & +26 & -22 & $37 / 37$ & $38 / 38$ \\
\hline $57 \mathrm{Co}$ & $c$ & $3 \mathbf{3 6}$ & 4.62 & 1 & 9.11 & +97 & +25 & $37 / 37$ & $37 / 386$ \\
\hline
\end{tabular}

Fig. 7. Global 2010 performance.

validation of uncertainties, the confidence with customer's requirements and the identification of problems in vitro interlaboratories comparison exercice is also the occasion to exchange their own experience with the goal to improve their quality of results.

Over the years, the proficiency testing programs have become an essential instrument for the management of radiotoxicology laboratories and the credibility of the analytical results obtained. 72 laboratories from 20 different countries participated in the last 2010 exercise. However, the goal of the laboratories taking part in these annual exercises is not only to check the accuracy of their results, but the analytical discussions and the opportunity to exchange experiences enrich the group's general competence.

For further information, please visit the PROCORAD website at: www.procorad.org.

\section{References}

1. ISO/IEC 17025, General requirements for the competence of testing and calibration laboratories

2. P. Bérard, J.C. Harduin, F. Briot, D. Cavadore, International RadioBioassay quality controls, Radiat. Prot. Dosim. 79, 509-512 (1998)
3. ISO/IEC 17043, Conformity assessment - General requirements for proficiency testing (2010)

4. P. Bérard, J.C. Harduin, D. Cavadore, Interlaboratory Comparisons: determination of actinides in excreta, J. Radioanal. Nucl. Chem. 197, 357-368 (1995)

5. P. Bérard, A. Montègue, F. Briot, Procorad's international intercomparisons highlight the evolution of techniques used to determine uranium in urine, Radiat. Prot. Dosim. 105, 447-450 (2003)

6. FD CEN/TR 10345, Guideline for statistical data treatment of interlaboratory tests for validation of analytical methods (A06-002) (2008)

7. FD ISO/TR 22971, Accuracy (trueness and precision) of measurement methods and results- Practical guidance for the use of ISO 5725-2:1994 in designing, implementing and statistically analysing interlaboratory repeatability and reproducibility results (X06-044) (2005)

8. NF ISO 13538, Statistical methods for use in proficiency testing by interlaboratory comparisons (X06-510) (2005)

9. American National Standards Institute (ANSI), Performance Criteria for Radiobioassay (1996), HPS N13.30-1996

10. ISO 12790-1 standard, Radiation Protection Performance Criteria for Radiobioassay - Part 1: General Principles 